Ne'am R. Al-Saleem

BDS, MSc (Assis lect)

\section{The shear bond strength of moisture ins- ensitive orthodontic bonding.}

\author{
Dept of Pedod, orthod, and Prev Dentistry \\ College of Dentistry, University of Mosul
}

\begin{abstract}
Aims: To assess the effect of water contamination on the shear bond strength of moisture insensitive Fuji Lc. glass ionomer and to compare it with the shear bond strength of (transbond) light cure composite. Materials and methods: Sixty extracted human premolar were cleaned and dried and embedded in cylinders filled with dental stone and the teeth were divided into three groups (20 teeth of each) which were etched and washed and dried the teeth in group 3 were slightly moistened in a cotton pellet and then the brackets were bonded to the teeth according to the manufacture instructions. Group1: using light cure composite (transbond); Group2: using glass ionomer cement (Fuji Lc.) in dry condition; Group3: using glass ionomer cement (Fuji Lc.) in moist condition. The shear bond strength was measured using instron mechanical test machine. Statistical analysis including descriptive statistics were applied to the results and then the findings were compared among the three groups using ANOVA and Duncan tests. Results: Light cure composite (transbond) had the highest shear bond strength followed by Fuji Ortho. Lc. (moist condition) and then Fuji Lc. (dry condition), which had the significant lowest shearbond strength. Conclusions: Transbond light cure composite had the highest shear bond strength. The presence of moisture enhances the shear bond strength of light cure glass ionomer cement (Fuji Lc.).

Key words: Shear bond strength, moisture insensitive, orthodontic bonding.
\end{abstract}

Al-Saleem NR. The shear bond strength of moisture insensitive orthodontic bonding. Al-Rafidain Dent J. 2007; 7(1): 61-65.

Received: 22/1/2006 Sent to Referees: 25/1/2006 Accepted for Publication: 23/3/2006

\section{INTRODUCTION}

The term adhesion is used in different ways and fields. Adhesion implies the existence of intratomic or intermolecular attraction. ${ }^{(1)}$ In dentistry, we often use this term for refering to mechanical union in which it is produced by microretention without any chemical interaction between substrates. By mechanical retention, we understand, for instance, the union produced on enamel etched with resin adhesive systems. ${ }^{(2)}$

Since, the advent of bonding bracke$\mathrm{ts}^{(3)}$, clinicians and researchers have worked to improve the qualities of bonding agents. The qualities that have been of most interest include bond strength, adequate working time, shorter cure time, improved case of use and the introduction of cariogenic agents. ${ }^{(4)}$

When phosphoric acid is applied to the enamel, selective dissolution produces microporosities into which fluid monomer can penetrate. ${ }^{(5)}$ The resin seeps into the porous enamel, and when polymerized a micromechanical union between this and the enamel occurs. ${ }^{(6)}$ At first the union between an orthodontic bracket and resin is sole a mechanical union, but advance in formation of resin have lead to the production of resin cement capable of forming chemical union with enamel, dentin, ceramic, metals and composite material. ${ }^{(6,7)}$

Adhesives have been altered from acrylics and epoxies to epoxy-acrylates to glass ionomer fluoride releasing cements to the current resin modified glass ionomer cement. $^{(8-11)}$

The time involved in enamel etching with phosphoric acid have been reduced from 60 or 30 seconds to 10 seconds. Failure of orthodontic bonded attachments and brackets is mostly attributed to contamination of the enamel surface. To overcome this problem, materials have been developed that purportedly overcome the moisture 
and contaminants present in the oral environment. ${ }^{(12)} 10 \%$ poly acrylic acid can be used to faster bonding to moist, unetched dry surface when using resin modified glass ionomer cements. Chemical (self) curing adhesives have been reformulated to serve as light curing adhesives. ${ }^{(8,9)}$ Glass ionomer cements, and due to their chemical composition, have an inherent adhesive capacity ${ }^{(5,6)}$, they adhere chemically to enamel, to dentin, to non precious metal and plastic. ${ }^{(13-16)}$

However, studies suggested that the new generation of resin-modified glass ionomer cements, which include varying amounts of photocurable monomer, had improved properties including bond strength. ${ }^{(17-22)}$

Fuji Ortho. Lc. is a light cured resin modified glass ionomer adhesive formulated for bonding orthodontic brackets, attachments and appliances to enamel, porcelain and metal restorations. As glass ionomer it self adhesive to enamel and must be used in the presence of moisture. ${ }^{(16)}$

The aims of this study were to assess the effect of water contamination on the shear bond strength of moisture insensitive Fuji Lc. glass ionomer and to compare it with the shear bond strength of (transbond) light cure composite.

\section{MATERIALS AND METHOD}

A total of 60 extracted human upper right and left premolars were divided into 3 groups of 20 teeth each.

The teeth were washed in water to remove any traces of blood and placed in $1 \%$ thymol solution. Then, they were stored in distilled water which was changed periodically to avoid deterioration. The labial surfaces of the teeth were cleaned with flour pumice and a rubber cup, rinsed with distilled water, and dried with an air syringe free of oil and water. After that the roots embedded in cylinders containing dental stone. The tooth specimens were divided into three groups all were acid etched for 30 seconds with $37 \%$ phosphoric acid, rinsed with water for 30 seconds and dried with an air syringe for 15 seconds. The teeth in the third group were slightly moistened with moist cotton role before bonding.

Sixty metal premolars brackets (Lancer, USA) were used (mesh type). The base area of each bracket was calculated $\left(\right.$ mean $\left.=2.8 \times 3.6 \mathrm{~mm}^{2}\right)$ using digital vernia. The brackets in the three groups were bonded according to the manufacture instructions.

Group1: Light cure composite (transbond, 3 M Unitek Orthodontic Product, USA) bond; A layer of light cure bond liquid resin was applied on the tooth, and then cured for 20 seconds. Light cure bond paste was applied to the base of the bracket and pressed firmly onto the tooth. Excess adhesive was removed from arou-nd the base of the bracket, and it was light cured. Positioning the light on the mesial side of the bracket for 20 seconds and on the distal side for other 20 seconds.

Group 2: Hybrid GC Fuji Ortho Lc. (Japan). After etching, rinsing and drying, GC Fuji Ortho. conditioner were applied to the bonding surfaces of the teeth for 20 seconds. Then rinsed thoroughly, powder and liquid were mixed according to the manufacturer instruction, the bonding surface of the brackets was completely coated with the mixed adhesive, positioned on the tooth, pressed firmly against the enamel and the excess material was removed. The brackets were light cured for 10 seconds each from the occlusal, mesial, distal and gingival aspects.

Group 3: The same as group 2 but the tooth surface was moistened with cotton pellet before bonding of the brackets.

Bond strength test: Shear bond strength was measured with an Instron mechanical testing machine (Evanston, USA). The force required for debond each bracket was registered in Newtons and converted into Megapascals as ratio of Newtons to surface area of the bracket $(\mathrm{Mpa}=\mathrm{N} /$ $\mathrm{mm}^{2}$ ). To appropriately compare different bond test studies.

Statistical analysis; Mean, Standard deviation for bond strength to each group was performed. Also the bond strengths of the three groups were compared by the analysis of variance (ANOVA) and Duncan's Multible Range test at $p \leq 0.05$ significant level. 


\section{RESULTS AND DISCUSSION}

The mean, standard deviation of the shear bond strength of the three groups: light cure transbond composite, moisture insensitive glassionomer cement (Fuji type) in moist and dry conditions, are shown in (Table 1). Light cure transbond composite had the highest shear bond strength and the highest standard deviation followed by Fuji Lc. in moist condition and then Fuji Lc. in dry condition.

ANOVA test revealed a significant difference among the three group with $\mathrm{F}$ value $=12.14(\mathrm{Pr}>\mathrm{F}, 0.002)$ as shown in Table (2).

Table (3) showed the significant difference was seen between transbond light cure composite and Fuji Ortho Lc. glass ionomer (with moist condition) in one hand and Fuji Ortho Lc. glass ionomer (dry condition) on the other hand. This indicated that the bond strength of Fuji Lc. would be affected by the absence of moisture and would be reduced.

Failure of orthodontic attachments and brackets is mostly attributed to the contamination of enamel surface, to overcome this problem, materials like Fuji Ortho Lc. have been developed and according to the manufacturers this product can be used successfully for bonding brackets without etching and with the presence of moisture and contamination.

Nevertheless, Bishara et $a$. $^{(22)}$, and Larmour and Stirrups ${ }^{(23)}$ reported a significantly higher failure rates and less shear bond strength for Fuji Lc. than conventional composite resin based adhesives and suggested that the bond strength achieved may not be adequate to withstand normal occlusal loading and bond strength may be sufficient for low loading situations such as upper anterior teeth. However, bonding with Fuji Ortho Lc. using conventional etching technique results in an improvement in the bonding strength. The presence of moisture enhances the bonding strength too. This could be advantages from the clinical point of view especially for patients with an increased caries risk status due to the cariostatic action of fluoride release.

Table (1): Descriptive statistics (Mean and Standard deviation) of the shear bond strength (MPa) for the three groups.

\begin{tabular}{ccccc}
\hline Group & $\begin{array}{c}\text { Number } \\
\text { of sample }\end{array}$ & Mean \pm SD & Minimum Maximum \\
\hline light cure acrylic resin & 20 & $10.5316 \pm 2.7578$ & 12.453 & 5.416 \\
$\begin{array}{c}\text { Glassionomer cement (Fuji type) } \\
\text { in dry condition }\end{array}$ & 20 & $5.6997 \pm 1.3651$ & 7.903 & 3.683 \\
$\begin{array}{c}\text { Glassionomer cement (Fuji type) } \\
\text { in moist condition }\end{array}$ & 20 & $8.6751 \pm 2.2832$ & 12.453 & 4.926 \\
\hline
\end{tabular}

Table (2): ANOVA test demonstrate the difference among the three groups.

\begin{tabular}{cccccc}
\hline & DF & $\begin{array}{c}\text { Sum of } \\
\text { square }\end{array}$ & $\begin{array}{c}\text { Mean } \\
\text { square }\end{array}$ & F - value & Pr> F \\
\hline Source & 2 & 118.8247 & 59.4123 & & \\
error & 57 & 132.1421 & 4.8941 & 12.14 & 0.0002 \\
Corrected total & 59 & 250.9669 & & & \\
\hline
\end{tabular}

DF: Degree of freedom 
Table (3): Duncan test demonstrate the difference among the three groups.

\begin{tabular}{cccc}
\hline Group & $\begin{array}{c}\text { Number of } \\
\text { sample }\end{array}$ & Mean \pm SD & Duncan's group* \\
\hline Light cure acrylic resin & 20 & $10.5316 \pm 2.7578$ & $\mathrm{~A}$ \\
$\begin{array}{c}\text { Glassionomer cement (Fuji type) in } \\
\text { dry condition }\end{array}$ & 20 & $5.6997 \pm 1.3651$ & $\mathrm{~B}$ \\
$\begin{array}{c}\text { Glassionomer cement (Fuji type) in } \\
\text { moist condition }\end{array}$ & 20 & $8.6751 \pm 2.2832$ & $\mathrm{~A}$ \\
\hline
\end{tabular}

Different letters mean significant difference at $p \leq 0.05$; SD: Standard deviation.

\section{CONCLUSION}

Light cure composite (transbond) had the highest shear bond strength followed by Fuji Lc. (moist condition) and then Fuji Lc. (dry condition). No significant difference was seen between (transbond) light cure composite and glass ionomer cement Fuji type in moisture condition. Fuji Lc. (dried condition) had significantly lower shear bond strength than the other two groups which reflect the effect of the absence of moist on the bond strength of Fuji Lc.

\section{REFERENCES}

1. Vicente A, Bravo LA, Romero M, Ortiz AJ, Canteras M. A comparison of shear bond strength of a resin cement and two orthodontic resin adhesive systems. Angle Orthod. 2004; 75(1): 109-113.

2. Newnan GV. Bonding plastic orthodontic attachments to tooth enamel. JNJ Den Assoc. 1964; 35: 346-352.

3. Newnan GV. Clinical applications of direct and indirect bonding in orthodontics. Citted by: Barrer HG. Orthodontics: The State of Art. Philadelphia, Penn, University of Pennsylvania Press. 1981; Pp: 201-210.

4. Newnan GV. First direct bonding in orthodontia. Am J Orthod Dentofacial Orthop. 1992; 101: $201-210$.

5. Derrick R, Beech DR, Teherah J. Bonding of polymers to enamel: Influence of deposites during etching, etching time and period of water immersion. J Dent Res. 1980; 59: 1156-1161.

6. Erickson RL, Glasspoole EA. Adhesion ala estructura dentaria: comparacion de los ionomeros de vidrioly los composites. J Esthet Dent. 1995; 5: 1-26. (abstract)
7. Ireland AJ, Sherrif M. Use of an adhesive region for bonding orthodontic brackets. Eur J Orthod. 1994; 1: 27-34.

8. Bowen RC. Adhesive bonding of various materials to hard tooth tissues $\mathrm{V}$ : The effect of a surface active monomer on adhesion to dental substrates. J Dent Res. 1965; 44: 1369 - 1373.

9. Reynolds IR. A review of direct orthodontic bonding. Br J Orthod. 1979; 2: 171-178.

10. Wilson AD, Kent BE. A new translucent cement for dentistry. Br Dent $J$. 1972; 132: 133 - 135.

11. Swartz ML, Phillips RW, Clark HE. Long term release from glass ionomer cements. J Dent Res. 1984; 63: 158- 60.

12. Webster MJ, Nanda RS, Duncanson MGdr, Khajotia SS, Sinha PK. The effect of saliva on shear bond strength of hydrophilic bonding system. Am J Orthod Dentofacial Orthop. 2001; Jan 119(1): 54-50.

13. Glady SS, Vanmeerbeck B, Brean Y, Lanbrechts P, Vanherle G. Comparative physio-mechanical characterization of new hybrid restorative materials which conventional glass ionomer and resin composite restorative materials. $J$ Dent Res. 1996; 76: 883 - 894.

14. Van Meerbeck B, Xoshida X, Lambrechts P, Vanherle G, Kepgen T. Factors que inluencian el exito clinico de la adhesion ladentina la esmalte. Maxilaris. 1999; 14: 20-36. (abstract)

15. Fricker J, McLachlin M. Clinical studies of glass ionomer cements. Aust Orthod J. 1995; 9: 179 - 180.

16. Silverman E, Cohen M, Demke R, Silverman R. A new light cured glass ionomer cement that bonds brackets to teeth without etching in the presence of 
saliva. Am J Orthod Dentofac Orthop. 1995; 44: 1369-1373.

17. Cook PA, Youngson CC. A fluoride composite resin-an in vitro study of a new material for orthodontic bonding. Brit J Orthod. 1989; 16: 207-212.

18. Chan D, Swift E, Bishara S. In-vitro evaluation of a fluoride releasing orthodontic resin. J Dent Res. 1990; 69: 1576 -1579 .

19. Rezk - Lega F, Ogaard B. Tensile bond force of glass ionomer cements in direct bonding of orthodontic brackets: an invitro comparative study. Am J Orthod Dentofacial Orthop. 1991; 100: 357361.

20. Compton AM, Hondrum SO, Lorton L. Comparison of the shear bond strength of a light cured glass ionomer and che- mically cured glass ionomer for use as an orthodontic bonding agent. Am J Orthod Dentofacial Orthop. 1992; 101: 138-144.

21. McCarthy MF, Hondrum SO. Mechanical and bond strength properties of light cured and chemically cured glass ionomer cements. Am J Orthod Dentofac Orthop. 1994; 105: 135-141.

22. Bishara SE, Oisen ME, Damon P, Jakobsen JR. Evaluation of new lightcured orthodontic bonding adhesive. $A m$ J Orthod Dentofacial Orthop. 1998; 85: $333-340$.

23. Larmour CJ, Stirrups DR. An in vivo assessment of a resin modified glass ionomer cement in relation to bondind technique. Br J Orthod. 2001; 28(3): 207-210. 